\title{
The Effects of Nutritional Status on Educational Performance of Primary School Children in the Plantation Sector in Nuwara Eliya Educational Zone
}

\author{
M. Sri Gajapathy Sarma, D.G.N.G Wijesinghe ${ }^{{ }^{*}}$ and T. Sivananthawerl ${ }^{2}$
}

Postgraduate Institute of Agriculture

University of Peradeniya

Sri Lanka

\begin{abstract}
The objective of this study was to determine the effects of nutritional status on educational performance of the primary school children in the plantation sector in Nuwara Eliya educational zone. A cross-sectional study involving 802 Grade-4 children was conducted on a randomly selected 21 plantation schools in Nuwara Eliya zone. By measuring height and weight using standard methods, indicators such as height-for-age, weight-for-age and body mass index-for-age were computed and used to define stunting, underweight and thinness to indicate nutritional status. The educational performance of children was assessed by using end-term examination marks obtained for Tamil and Mathematics subjects and for the overall subject average. The prevalence of stunting, underweight and thinness in the study group was $32 \%, 50 \%$ and $34 \%$, respectively. All indicators were significantly higher $(p<0.05)$ in males than in females. The educational performance of females was higher than males, the differences being statistically significant except in Mathematics ( $p=0.075)$. The low level of educational performance (marks $<40 \%)$ in Tamil, Mathematics and overall subject average was significantly higher $(p<0.05)$ among the underweight and stunted children than that of the normal children. The height-for-age and weight-for-age Z-scores showed significant positive associations $(p<0.05)$ with Tamil, Mathematics and overall subject average marks while BMI-for-age Z-score showed significant positive associations $(p<0.05)$ with only Mathematics and overall subject average. It appears that undernutrition in the primary school children of the plantation sector has led to a low level of educational performance, which could affect their quality of life in the long-term.
\end{abstract}

Keywords: Educational performance, nutritional status, plantation sector, school children, undernutrition.

\section{INTRODUCTION}

Children are considered the greatest national resource of any country who will build the future of the Nation. Schooling is an instrument of individual and social change, increasing the probabilities of general well-being (UNESCO, 1984). Primary education is a vital stage in the development of the consciousness and personality of the child as it is at this juncture that a whole new world of bright ideas and knowledge open up in front of their eyes. At this

Department of Food Science and Technology, Faculty of Agriculture, University of Peradeniya, Sri Lanka

Department of Crop Science, Faculty of Agriculture, University of Peradeniya, Sri Lanka.

Corresponding author: wijeng@yahoo.com 
stage children are extremely inquisitive and elementary education must encourage this tendency among the children.

Nutrition is an endogenous factor that affects the learning ability and skills before and after the child is in school (UNESCO, 1984). Several studies on the relationship between undernutrition, wasting, stunting and academic achievement have been published (Pollitt, 1990; Themane et al., 2003; Mukudi, 2003; Ivanovic et al., 2004 and Cueto, 2005) and all of them have reported significant associations between nutritional status indicators and cognitive test scores or school performance indicators.

The relationship between nutrition, health and educational achievement of school-age population in less-developed countries has been of interest to many researchers due to the frequent observation that many children did not complete primary education and those who completed, did not perform well as children in the developed countries. Several studies in developing countries found that height-for-age, which is an indicator of stunting, is related to educational achievement (Shariff et al., 2000; Glewwe et al., 2001; Alderman et al., 2001 and Aturupane et al., 2006). Height-for-age reflects the accumulation of nutritional deprivation throughout the years, which may consequently affect the cognitive development of the children (Shariff et al., 2000).

A study conducted by MRI, Sri Lanka (2002) had shown that the highest number of stunted children was found from the Central (26.6\%) and Uva (23.8\%) Provinces where the wasting prevalence was less than $15 \%$. The prevalence of underweight was also higher in Central (39.6\%) and Uva (36.4\%) Provinces. From the school-age children in the plantation sector of Sri Lanka, only $58 \%$ attended up to the completion of primary schooling. The dropout rate for the estate sector was high-averaging $8.4 \%$ at Grade- 5 as compared to just $1.4 \%$ for the whole country. According to Ministry of Education data, the male transition rate from primary to secondary level in the Nuwara-Eliya district is far lower than other districts. Many boys are compelled to join the workforce (Wijesiriwardane and Amaranath, 2009).

On this backdrop, there is a necessity to find the effects of nutritional status on educational performance of children in the plantation sector schools. The present study investigates this relationship using primary school children in Nuwara-Eliya educational zone.

\section{METHODOLOGY}

\section{Study design, population and sample}

A cross-sectional study was conducted in Nuwara-Eliya educational zone between November 2009 and July 2010. In this zone, among the total students, $78.3 \%$ were studying in Tamil medium schools and living in the estate sector. Out of four educational divisions in the zone, three divisions cover Tamil schools (Nuwara-Eliya Tamil-1, Tamil-2 and Tamil-3) and from among them divisions 2 and 3 were selected for this study. In the study area, 26 schools are having primary to ordinary level classes and from them 21 schools were selected randomly which included Type 1AB (schools with advanced level science stream), Type 1C (schools with advanced level arts and commerce streams) and Type 2 (schools having up to ordinary level) categories. From these 21 schools 802 Grade- 4 students were recruited for the study. The students suffering from genetic disorders or differently-able were excluded from the study since those conditions are reported to affect the learning capacity (King et al., 1981 and Werner, 1987). 
Permission for the study was obtained in writing from the Zonal Director of Nuwara-Eliya Educational Zone and Divisional Directors of Tamil Division 1 and 2. Approval from all school principals and class teachers were obtained. All participants and their parents were informed about the study and their verbal consent was obtained prior to the study.

\section{Assessment of nutritional status (Anthropometry)}

Just before the third-term examination period anthropometric measurements such as height and weight of students were taken in the classroom according to the standard procedures (WHO, 1995) using standard equipment. NCHS/CDC (2000) references were used to define nutritional indices. Z-scores of Height-for-age (HAZ), Weight-for-age (WAZ) and Body mass index-for-age (BMIZ) were used to define stunting, underweight and thinness, respectively using a cut-off value of $<-2$ standard deviation from the median value of the references.

\section{Assessment of educational performance}

The students' educational performance was assessed by using their end-term examination marks which were based on the curriculum designed by the Ministry of Education in Sri Lanka .The successful development of literacy and numeracy skills (essential skills) during the primary school years will be crucial for educational success in post-primary school and in enabling every individual to realize his or her social and vocational potential (NCCA, 1999). Since all plantation sector primary school children follow Tamil (language) and Mathematics subjects, these two subjects were chosen to represent the above two skills. The percentage marks obtained for Tamil and Mathematics subjects and for overall subjects' average were considered for their performance assessment. To examine the effect of nutritional status on educational performance subject marks were divided into 2 categories as low and high based on a cut-off mark of $40 \%$.

\section{Data analysis}

Epi Info 3.4.3 version (CDC, USA) software was used to calculate the Z-score of weight-forage, height-for-age and BMI-for-age of the children. Data analyses were carried out using SPSS for windows version 16.0 statistical software. Test for comparison of means between groups were done using the Student's t-test and one way ANOVA test. Differences between groups were tested using Pearson's Chi-square test and odds ratios. The relationship between nutritional variables and learning achievements were studied using Pearson's correlation coefficient test. A probability value of $<0.05$ was considered as significant.

\section{RESULTS}

Among the 802 participants whose height and weight were measured, 562 (70.1\%) completed the evaluation test for both Tamil and Mathematics subjects. Children who sat for only one of the two subjects or whose marks were not made available were not considered for the educational assessment. The distribution of children by gender and type of school is given in Table 1. 
Table 1. Distribution of study children by gender and type of school

\begin{tabular}{llcc}
\hline \multirow{2}{*}{ Variable } & \multicolumn{1}{c}{ Level } & $\begin{array}{c}\text { Anthropometric Assessment } \\
\mathbf{n}(\%)\end{array}$ & $\begin{array}{c}\text { Educational Assessment } \\
\mathbf{n}(\mathbf{\%})\end{array}$ \\
\hline Gender & Male & $410(51.1)$ & $283(50.4)$ \\
\multirow{3}{*}{ Type of school } & Female & $392(48.9)$ & $279(49.6)$ \\
& 1AB & $165(20.6)$ & $119(21.2)$ \\
& 1 C & $352(43.9)$ & $255(45.4)$ \\
& Type 2 & $285(35.5)$ & $188(33.5)$ \\
\hline
\end{tabular}

\section{Anthropometric assessment}

The students' age ranged from 8.8 to 12.6 years with the mean value of $9.6 \pm 0.5$. The nutritional indicators, weight-for-age, height-for-age and BMI-for-age of male children were lower than that of female children (Table 2).

Table 2. General characteristics of study children by gender

\begin{tabular}{lrrr}
\hline \multirow{2}{*}{ Variable } & \multicolumn{2}{c}{ Mean \pm SD } & \multirow{2}{*}{ value $^{*}$} \\
\cline { 2 - 3 } Age (year) & \multicolumn{1}{c}{ Male } & \multicolumn{1}{c}{ Female } & \multirow{2}{*}{0.807} \\
Weight (kg) & $9.6 \pm 0.5$ & $9.6 \pm 0.5$ & 0.075 \\
Height $(\mathrm{cm})$ & $22.7 \pm 3.4$ & $23.2 \pm 4.1$ & 0.373 \\
BMI (kg/m ${ }^{2}$ ) & $126.3 \pm 6.1$ & $126.7 \pm 6.4$ & 0.089 \\
Weight-for-age (WAZ) & $14.2 \pm 1.4$ & $14.4 \pm 1.8$ & $<0.001$ \\
Height-for-age (HAZ) & $-2.2 \pm 1.2$ & $-1.9 \pm 1.0$ & 0.033 \\
BMI-for-age (BMIZ) & $-1.6 \pm 1.0$ & $-1.5 \pm 1.0$ & 0.002 \\
\hline
\end{tabular}

"Student's t test

Table 3 summarizes the general characteristics of study children by the type of school. The students' weight, height, BMI, weight-for-age, height-for-age and BMI-for-age were decreasing with the type of school ( $1 \mathrm{AB}>1 \mathrm{C}>$ Type 2$)$ and the differences were statistically significant.

Table 3. General characteristics of study children by type of school

\begin{tabular}{|c|c|c|c|c|c|}
\hline \multirow{2}{*}{ Variable } & \multicolumn{3}{|c|}{ Mean \pm SD } & \multirow{2}{*}{$F$ value } & \multirow{2}{*}{$p$ value ${ }^{*}$} \\
\hline & Type AB & Type C & Type 2 & & \\
\hline Age (year) & $9.6 \pm 0.4$ & $9.5 \pm 0.5$ & $9.6 \pm 0.5$ & 3.510 & 0.030 \\
\hline Weight (kg) & $24.1 \pm 4.6$ & $22.9 \pm 3.8$ & $22.4 \pm 2.8$ & 12.384 & $<0.001$ \\
\hline Height (cm) & $128.2 \pm 6.5$ & $126.3 \pm 5.6$ & $125.8 \pm 6.7$ & 8.132 & $<0.001$ \\
\hline BMI $\left(\mathrm{kg} / \mathrm{m}^{2}\right)$ & $14.6 \pm 2.0$ & $14.3 \pm 1.5$ & $14.1 \pm 1.5$ & 4.993 & 0.007 \\
\hline WAZ & $-1.8 \pm 1.2$ & $-2.1 \pm 1.2$ & $-2.2 \pm 1.0$ & 9.616 & $<0.001$ \\
\hline HAZ & $-1.3 \pm 1.0$ & $-1.5 \pm 0.9$ & $-1.6 \pm 1.0$ & 7.611 & 0.001 \\
\hline BMIZ & $-1.4 \pm 1.2$ & $-1.6 \pm 1.1$ & $-1.8 \pm 1.4$ & 4.804 & 0.008 \\
\hline
\end{tabular}


As shown in Fig. 1, the prevalence of underweight, stunting and thinness in the study group was $50.4 \%, 32.2 \%$ and $33.7 \%$ respectively. Percentage of children having any kind of undernutrition (stunting, underweight, thinness or any 2 or 3 combinations) was $60.2 \%$. The prevalence of underweight, stunting and thinness was significantly higher in males than in females. Odds ratio analysis showed that male children were having 1.3 times $(\mathrm{OR}=1.335$, 95\% CI 1.012-1.763) higher chance of being underweight, 1.6 times $(\mathrm{OR}=1.553,95 \% \mathrm{CI}$ 1.151- 2.095) higher chance of being stunted and 1.4 times $(\mathrm{OR}=1.431,95 \% \mathrm{CI} 1.066-1.922)$ higher chance of being thin than female children.

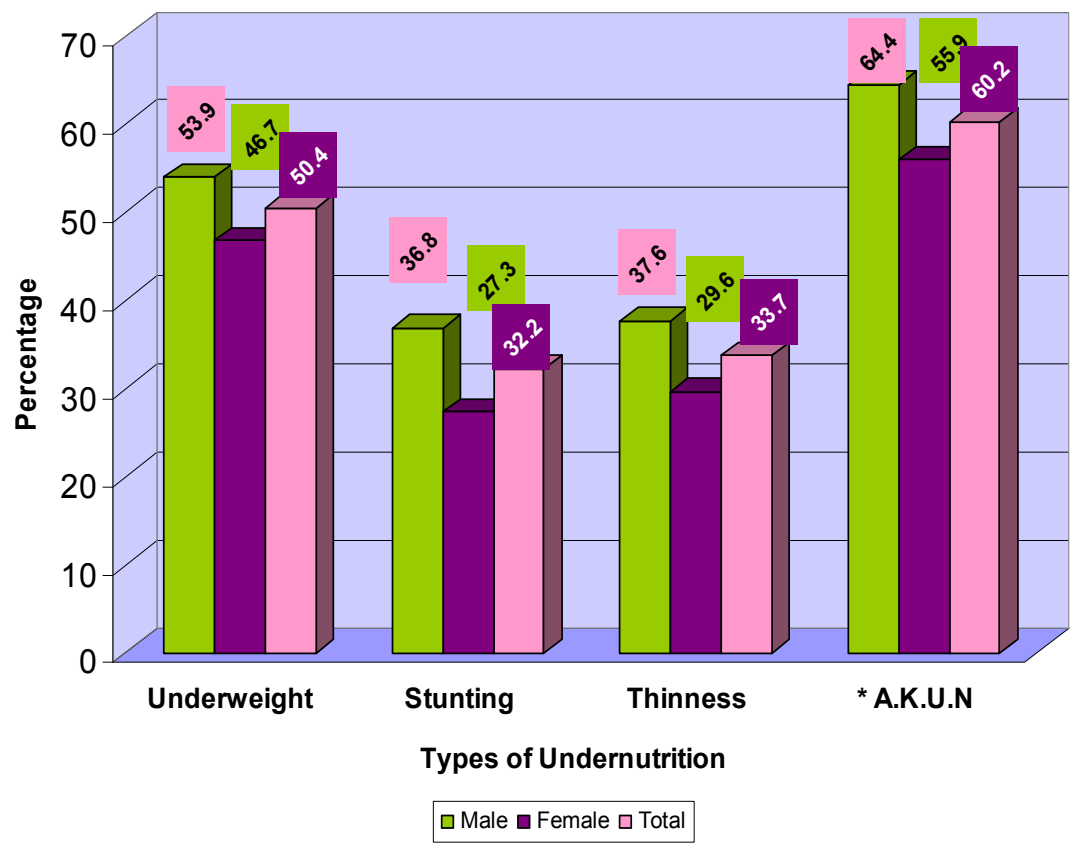

- $\quad$ A.K.U.N - Any kind of undernnutrition

Fig. 1. Prevalence of undernutrition by gender

Table 4 illustrates that, the prevalence of underweight, stunting and thinness was significantly increasing with the type of school in the order type $1 \mathrm{AB}<$ type $1 \mathrm{C}<$ Type 2 .

Table 4. Prevalence of undernutrition by type of school

\begin{tabular}{lrrrrr}
\hline \multirow{2}{*}{ Variable } & \multirow{n}{*}{} & \multicolumn{4}{c}{ Prevalence (\%) } \\
\cline { 3 - 6 } & & Underweight & Stunting & Thinness & A.K.U.N* \\
\hline Type 1AB & 165 & 35.8 & 24.8 & 26.1 & 44.2 \\
Type 1C & 352 & 51.1 & 31.5 & 32.4 & 58.5 \\
Type 2 & 285 & 57.9 & 37.2 & 39.6 & 71.6 \\
& $\chi 2$ value & 20.631 & 7.414 & 9.100 & 33.358 \\
& $p$ value & $<0.001$ & 0.025 & 0.011 & $<0.001$ \\
\hline
\end{tabular}

*A.K.U.N - Any kind of undernutrition 


\section{Educational performance}

The mean marks obtained for Tamil and Mathematics subjects and the overall subject average of the study group by gender and type of school are shown in Table 5 .

Table 5. Mean subject marks by gender and type of school

\begin{tabular}{ccrrr}
\hline \multirow{2}{*}{ Variable } & $\mathbf{n}$ & \multicolumn{3}{c}{ Mean \pm SD } \\
\cline { 3 - 5 } & & Tamil & Mathematics & O.S Average $^{+}$ \\
\hline Gender & & & & \\
Male & 283 & $42.2 \pm 25.5$ & $40.7 \pm 24.6$ & $42.2 \pm 19.0$ \\
Female & 279 & $51.3 \pm 24.3$ & $44.3 \pm 24.3$ & $47.6 \pm 18.3$ \\
& $p$ value $^{*}$ & $<0.001$ & 0.075 & 0.001 \\
Type of School & & & & \\
1 AB & 119 & $56.4 \pm 25.3$ & $50.0 \pm 24.5$ & $49.4 \pm 19.1$ \\
1 C & 255 & $46.3 \pm 25.0$ & $44.2 \pm 24.8$ & $45.0 \pm 20.7$ \\
Type 2 & 188 & $41.1 \pm 24.0$ & $35.5 \pm 22.2$ & $42.0 \pm 15.2$ \\
& $p$ value ${ }^{* *}$ & $<0.001$ & $<0.001$ & 0.003 \\
Total & 562 & $46.7 \pm 25.3$ & $42.5 \pm 24.5$ & $44.9 \pm 18.8$ \\
\hline *Student's t test & ** One way ANOVA test +O.S.Average - Overall subject average
\end{tabular}

Female students had higher marks than male students for Tamil and Mathematics subjects and for overall subject average, differences being statistically significant except in Mathematics. Also the three average marks were significantly different with the type of school in the order Type $1 \mathrm{AB}>$ Type $1 \mathrm{C}>$ Type 2 .

Table 6. Mean subject marks by nutritional status of children

\begin{tabular}{|c|c|c|c|c|}
\hline \multirow{2}{*}{ Variable } & \multirow{2}{*}{$\mathbf{n}$} & \multicolumn{3}{|c|}{ Mean \pm SD } \\
\hline & & Tamil & Mathematics & O.S Average $^{+}$ \\
\hline \multicolumn{5}{|l|}{ Weight-for-age } \\
\hline Underweight $(<-2 \mathrm{SD})$ & 404 & $42.5 \pm 25.0$ & $38.2 \pm 23.9$ & $42.1 \pm 18.2$ \\
\hline Normal $(\geq-2 S D)$ & $\begin{array}{c}398 \\
p \text { value }\end{array}$ & $\begin{array}{r}51.0 \pm 25.0 \\
<0.001\end{array}$ & $\begin{array}{r}46.8 \pm 24.4 \\
\quad<0.001\end{array}$ & $\begin{array}{r}47.7 \pm 19.1 \\
<0.001\end{array}$ \\
\hline \multicolumn{5}{|l|}{ Height-for-age } \\
\hline Stunted $(<-2 \mathrm{SD})$ & 258 & $41.3 \pm 25.3$ & $38.0 \pm 24.3$ & $41.6 \pm 18.4$ \\
\hline Normal $(\geq-2 S D)$ & $\begin{array}{c}544 \\
p \text { value }^{*}\end{array}$ & $\begin{array}{r}49.5 \pm 24.9 \\
<0.001\end{array}$ & $\begin{array}{r}44.8 \pm 24.3 \\
0.002\end{array}$ & $\begin{array}{r}46.6 \pm 18.8 \\
0.003\end{array}$ \\
\hline \multicolumn{5}{|l|}{ BMIZ } \\
\hline Thinness $(<-2 \mathrm{SD})$ & 270 & $45.5 \pm 25.7$ & $40.2 \pm 24.7$ & $43.5 \pm 19.1$ \\
\hline Normal ( $\geq-2 S D)$ & $\begin{array}{c}532 \\
p \text { value }^{*}\end{array}$ & $\begin{array}{r}47.3 \pm 25.2 \\
0.432\end{array}$ & $\begin{array}{r}43.6 \pm 24.3 \\
0.117\end{array}$ & $\begin{array}{r}45.6 \pm 18.7 \\
0.201\end{array}$ \\
\hline \multicolumn{5}{|l|}{ Any kind of undernutrition } \\
\hline Present & 483 & $43.0 \pm 24.8$ & $39.2 \pm 24.0$ & $42.7 \pm 18.0$ \\
\hline Absent & $\begin{array}{r}319 \\
p \text { value }\end{array}$ & $\begin{array}{r}51.3 \pm 25.2 \\
<0.001\end{array}$ & $\begin{array}{r}46.7 \pm 24.5 \\
<0.001\end{array}$ & $\begin{array}{r}47.7 \pm 19.5 \\
0.002\end{array}$ \\
\hline
\end{tabular}


Table 6 reveals that the children who were having underweight, stunting or any kind of undernutrition had significantly lower achievements in Tamil, Mathematics and overall subject average than the normal children.

As evident in Table 7, compared to normal children a low level of educational performance (marks $<40 \%$ ) was seen in underweight children for Tamil (OR=1.614, 95\% CI 1.149 2.266) and Mathematics (OR=1.700, 95\% CI $1.218-2.374)$ subjects and for the overall subject average (OR=1.677, 95\% CI $1.196-2.351)$. The same pattern was observed in the stunted children where the low level of performance was significantly higher for Tamil $(\mathrm{OR}=1.625,95 \% \mathrm{CI} 1.140-2.314)$, Mathematics $(\mathrm{OR}=1.513,95 \% \mathrm{CI} 1.064-2.152)$ and for overall subject average $(\mathrm{OR}=1.677,95 \%$ CI $1.196-2.351)$ than for normal children. Similarly, the low level performance was higher in Tamil (OR=1.507, 95\% CI $1.070-$ 2.123), Mathematics $(\mathrm{OR}=1.569,95 \% \mathrm{CI} 1.122-2.194)$ and the overall subject average $(\mathrm{OR}=1.499,95 \%$ CI $1.066-2.106)$ for children having any kind of undernutrition than normal children.

Table 7. Prevalence of low level of educational performance (marks $<40 \%$ ) by nutritional status of children

\begin{tabular}{|c|c|c|c|c|}
\hline \multirow{2}{*}{ Variable } & \multirow{2}{*}{$\mathbf{n}$} & \multicolumn{3}{|c|}{ Prevalence (\%) } \\
\hline & & Tamil & Mathematics & O. S. A* \\
\hline \multicolumn{5}{|l|}{ Weight-for-age } \\
\hline Underweight $(<-2 S D)$ & 282 & 46.1 & 55.0 & 48.2 \\
\hline \multirow[t]{3}{*}{ Normal ( $\geq-2 \mathrm{SD})$} & 280 & 34.6 & 41.8 & 35.7 \\
\hline & $\chi^{2}$ value & 7.659 & 9.771 & 9.031 \\
\hline & $p$ value & 0.006 & 0.002 & 0.003 \\
\hline \multicolumn{5}{|l|}{ Height-for-age } \\
\hline Stunting $(<-2 \mathrm{SD})$ & 191 & 48.2 & 56.5 & 48.7 \\
\hline \multirow[t]{3}{*}{ Normal ( $\geq-2 S D)$} & 371 & 36.4 & 44.2 & 38.5 \\
\hline & $\chi^{2}$ value & 7.266 & 7.687 & 5.329 \\
\hline & $p$ value & 0.007 & 0.006 & 0.021 \\
\hline \multicolumn{5}{|l|}{ BMIZ } \\
\hline Thinness $(<-2 \mathrm{SD})$ & 192 & 43.2 & 51.0 & 44.8 \\
\hline \multirow{3}{*}{ Normal ( $\geq-2 S D)$} & 370 & 38.9 & 47.0 & 40.5 \\
\hline & $\chi^{2}$ value & 0.975 & 0.816 & 0.938 \\
\hline & $p$ value & 0.323 & 0.366 & 0.33 \\
\hline \multicolumn{5}{|l|}{ Any kind of undernutrition } \\
\hline Present & 313 & 44.7 & 53.4 & 46.3 \\
\hline \multirow[t]{3}{*}{ Absent } & 249 & 34.9 & 42.2 & 36.5 \\
\hline & $\chi^{2}$ value & 5.519 & 6.948 & 5.445 \\
\hline & $p$ value & 0.019 & 0.008 & 0.020 \\
\hline
\end{tabular}

O.S.A *- Overall subject average

\section{Relationship between nutritional indicators and educational performance}

Table 8 shows that all nutritional indicators (WAZ, HAZ and BMIZ) had significant positive associations $(p<0.05)$ with learning achievement of students in the study as indicated by percentage marks obtained for Tamil and Mathematics subjects and the overall subject average. However, BMIZ failed to show a significant positive association with the subject Tamil $(P=0.058)$. While all nutritional indicators showed significant positive associations 
with Tamil, Mathematics and overall average marks of male students in female students, only WAZ showed a significant positive association with Mathematics.

Table 8. Pearson's correlation coefficients ( $r$ ) between nutritional indicators and educational performance of children by gender

\begin{tabular}{llcccccc}
\hline \multirow{2}{*}{$\begin{array}{l}\text { Nutritional } \\
\text { indicator }\end{array}$} & Subject & \multicolumn{2}{c}{ Male } & \multicolumn{2}{c}{ Female } & \multicolumn{2}{c}{ Total } \\
\cline { 3 - 8 } & & $\mathbf{r}$ & $\boldsymbol{p}$ & $\mathbf{r}$ & $\boldsymbol{p}$ & $\mathbf{r}$ & $\boldsymbol{p}$ \\
\hline WAZ & Tamil & 0.274 & $<0.001$ & 0.065 & 0.280 & 0.198 & $<0.001$ \\
& Mathematics & 0.283 & $<0.001$ & 0.126 & 0.035 & 0.217 & $<0.001$ \\
& Average & 0.262 & $<0.001$ & 0.085 & 0.159 & 0.196 & $<0.001$ \\
& & & & & & & \\
HAZ & Tamil & 0.236 & $<0.001$ & 0.091 & 0.130 & 0.178 & $<0.001$ \\
& Mathematics & 0.228 & $<0.001$ & 0.094 & 0.116 & 0.168 & $<0.001$ \\
& Average & 0.207 & $<0.001$ & 0.059 & 0.327 & 0.145 & 0.001 \\
& & & & & & & \\
BMIZ & Tamil & 0.138 & 0.020 & -0.009 & 0.885 & 0.080 & 0.058 \\
& Mathematics & 0.163 & 0.006 & 0.074 & 0.216 & 0.123 & 0.003 \\
& Average & 0.153 & 0.010 & 0.042 & 0.486 & 0.109 & 0.010 \\
\hline
\end{tabular}

The correlation between nutritional indicators and educational performance of students by type of school is given in Table 9.

Table 9. Pearson correlation coefficients $(r)$ between nutritional indicators and educational performance of children by type of school

\begin{tabular}{lrrrrrrr}
\hline $\begin{array}{l}\text { Nutritional } \\
\text { indicator }\end{array}$ & Subject & \multicolumn{2}{c}{ Type AB } & \multicolumn{2}{c}{ Type C } & \multicolumn{2}{c}{ Type 2 } \\
\cline { 3 - 8 } & & \multicolumn{1}{c}{$\mathbf{r}$} & $\boldsymbol{p}$ & $\mathbf{r}$ & $\boldsymbol{p}$ & $\mathbf{r}$ & $\boldsymbol{p}$ \\
\hline WAZ & Tamil & 0.296 & 0.001 & 0.143 & 0.023 & 0.128 & 0.080 \\
& Mathematics & 0.332 & $<0.001$ & 0.151 & 0.016 & 0.159 & 0.029 \\
& Average & 0.299 & 0.001 & 0.151 & 0.016 & 0.131 & 0.073 \\
HAZ & & & & & & & \\
& Tamil & 0.351 & $<0.001$ & 0.127 & 0.042 & 0.065 & 0.374 \\
& Mathematics & 0.396 & $<0.001$ & 0.163 & 0.009 & -0.042 & 0.569 \\
& Average & 0.357 & $<0.001$ & 0.135 & 0.031 & -0.038 & 0.606 \\
BMIZ & & & & & & & \\
& Tamil & 0.093 & 0.314 & 0.084 & 0.180 & 0.032 & 0.162 \\
& Mathematics & 0.115 & 0.212 & 0.063 & 0.316 & 0.162 & 0.026 \\
& Average & 0.113 & 0.222 & 0.093 & 0.138 & 0.110 & 0.131 \\
\hline
\end{tabular}

When the nutritional indicators and the subject marks of the three types of schools were compared, WAZ and HAZ had significant positive associations with Tamil, Mathematics and overall subject average marks in type $1 \mathrm{AB}$ and type $1 \mathrm{C}$ schools. In Type 2 schools only mathematics showed a significant positive association with WAZ and BMIZ. 


\section{DISCUSSION}

In this cross-sectional study a higher prevalence of underweight $(50.4 \%)$ was observed compared to stunting $(32.2 \%)$ or thinness $(33.7 \%)$ among Grade-4 children in plantation sector schools in Nuwara-Eliya educational zone. This is slightly higher than the findings of the MRI survey, Sri Lanka (2002) of 5-9 year-old children which indicated that the prevalence of undernutrition in the Central Province was 39.6\% underweight, $26.6 \%$ stunted and $14.9 \%$ wasted. The main reason for the higher values observed in the present study may be due to poor socio-economic status of the study sample although the variations in the age, area of sampling and the study time period could also contribute to the differences.

The present study indicated that male children had 30\% higher chance of being underweight, $60 \%$ higher chance of being stunted and $40 \%$ higher chance of being thin than the female children. This difference may be due to strict social control for female children in the estate sector than town areas. Females have better physical access to available food, although boys in general spend more time playing outside than girls. The physical activity level, which is higher in males than in females would lead to high energy loss and high undernutrition in males than in females. Present study findings concur with some previous studies in Sri Lanka (MRI, 2002), Malaysia (Shariff et al., 2000), East of Uganda (Acham et al., 2008) and Zanzibar (Stoltzfus et al., 1997). In contrast another Sri Lankan study in Colombo urban schools (Thilakarathne and Wijesinghe, 2011) showed that girls had a significantly higher prevalence of undernutrition than boys. On the other hand, Mian et al. (2002) reported that, no association exists between nutritional status and gender among school children in Pakistan.

Findings of the present study also revealed that the educational performance of female was significantly higher than males except in Mathematics. This is in agreement with the study in Vietnam (Hall et al., 2001) which reported that boys had a significantly lower test score than girls in Vietnamese $(P<0.001)$ but not in Mathematics $(P=0.52)$. A Malaysian study (Shariff et al., 2000) reported that male children were at risk of poor growth and lower educational achievement than female children. In Sri Lanka, most of the boys in the plantation sector spend their time on either working as helpers for their parents or playing outside with their friends and they tend to have a low interest in studies. In contrast, girls spend more time in their homes and have the opportunity to study more than boys.

According to the present study, the low level of educational performance (marks $<40 \%$ ) for Tamil (Language), Mathematics and overall subject average were higher among underweight and stunted children than the normal children. A study in East of Uganda (Acham et al., 2008) found that all nutritional indicators (HAZ, WAZ and BMI) had significant positive associations with learning achievement in English (Language) and mathematics of grade 4 children. In China, children with lower height-for-age were consistently far behind in their expected school grade (Jamison, 1986). The author concluded that because of the inconsistent effect of weight-for-height on grade attainment, height was a better predictor than weight. Shariff et al. (2000) reported that in Malaysia, among the three nutritional status indicators, height-for-age only showed a significant relationship with the educational achievement. In a Sri Lankan study of Grade-4 children, Aturupane et al. (2006) reported that height-for-age has a sizeable impact of examination scores, which was also consistent with results from Pakistan (Alderman et al., 2001) and the Philippines (Glewwe et al., 2001).

Further in the present study, height-for-age and weight-for-age Z-scores showed significant positive association with Tamil, Mathematics and overall subject average marks. BMI-for- 
age Z-score showed significant positive associations with Mathematics and overall subject average except in Tamil. An Ugandan study (Acham et al., 2008) reported that all nutritional indicators (HAZ, WAZ and BMIZ) had significant associations with learning achievement of children $(\mathrm{p}<0.05)$. Associations were positive particularly for Mathematics and English, but negative for life skills and oral comprehension.

Another finding in the present study was that the prevalence of undernutrition was significantly increasing with Type $1 \mathrm{AB}<$ Type $1 \mathrm{C}<$ Type 2 schools whereas the educational performance was significantly decreasing with Type $1 \mathrm{AB}>$ Type $1 \mathrm{C}>$ Type 2 schools. The reasons may be that the higher graded schools (1AB \& 1C) have better physical and human resources and are located on or closer to the small town areas than the Type 2 schools which are resource poor and situated in remote areas.

From the foregoing, there seem to be a general agreement that nutritional status affects the educational achievement. Hence, there is a need to improve nutritional level in the plantation sector to enhance the quality of life through better educational performance.

\section{CONCLUSION}

Chronic (stunting) and acute (underweight and thinness) undernutrition are highly prevalent among Grade-4 children in plantations sector schools in Nuwara-Eliya educational zone. Male children are more undernourished than female children. Educational performance of female children is significantly higher than male children. There is a significant positive association between nutritional indicators (WAZ, HAZ and BMIZ) and overall educational achievement.

\section{ACKNOWLEDGEMENT}

The Zonal Director and Additional Zonal Director of Education, Nuwara-Eliya, Divisional Directors of Tamil divisions 1 and 2, all principals and teachers of schools and students who participated in the study are gratefully acknowledged for their co-operation.

\section{REFERENCES}

Acham, H., Kikafunda, J.K., Oluka, S., Malde, M.K. and Tylleskar, T. (2008). Height, weight, body mass index and learning achievement in Kumi district, East of Uganda. Scientific Research and Essay Vol.3 (1), pp.1-8.

Alderman, H., Behrman, J.R., Lavy, V. and Menon, R. (2001). Child health and school enrollment: A longitudinal analysis. Journal of Human Resources 36, 185-205.

Aturupane, H., Glewwe, P. and Wisniewski, S. (2006). The impact of School Quality, SocioEconomic Factors and Child Health on Students' Academic Performance: Evidence from Sri Lankan Primary Schools. [on line]. [Accessed on 10.04.2012]. Available at http://faculty.apec.umn.edu/pglewwe/documents/SLed_ha5.pdf

Cueto, S. (2001). Height, weight and educational achievement in rural Peru. Food Nutr. Bull. 26(2) supplement. S251-260. 
Glewwe, P., Jacoby, H.G. and King, E.M., (2001). Early childhood nutrition and academic achievement: A longitudinal analysis. Journal of Public Economics 81, 345-68.

Hall, A., Khanh, L.N.B., Son, T.H., Dung, N.Q., Lansdown, R.G., Dat, D.T., Hanth,N.T., Moestue, H., Khoi, H.H. and Bundy, D.A.P. (2001). An association between chronic undernutrition and educational test scores in Vietnamese children. European Journal of Clinical Nutrition 55, 801-804.

Ivanovic, D.M., Perez. H.T., Olivares M.G., Diaz, N.S., Leyton, B.D., Ivanovic, R.M. (2004). Scholastic achievement: A multivariate analysis of nutritional, intellectual, socioeconomic, familial and demographic variables in Chilean school-age children. Nutrition $20,878-889$.

Jamison D.T (1986). Child malnutrition and school performance in China. J. Develop. Econ. 20(2), 299-309.

King, M. King, F. and Martodipoero, S. (1981). Primary child care: A manual for health workers. Oxford University Press, Oxford, UK.

Mian, R.M.A., Ali, M., Ferroni, P.A. and Underwood, P. (2002). The nutritional status of school-aged children in an urban squatter settlement in Pakistan. Pakistan Journal of Nutrition.1(3), 121-123.

MRI (2002). A Survey Report: Nutritional Problems among Sri Lankan Primary School Children Aged 5-9 years. Medical Research Institute, Colombo, Sri Lanka

Mukudi, E. (2003) Nutrition status, education participation and school Achievement among Kenyan middle-school children. Nutrition 19, 612-916.

NCCA - National Committee for Curriculum and Assessment (1999). Primary School Curriculum - Ireland [on line]. [Accessed on 20.10.2010]. Available at http://www.ncca.ie/uploadedfiles/curriculum/intro_eng.pdf

NCHS/CDC (2000).In EpiInfo 3.5.3 [on line]. [Accessed on 20.10.2010]. Available at http://www.cdc.gov/epiinfo/downloads.htm

Pollit, E. (1990). Malnutrition and infection in the classroom. Summary and Conclusions. Food Nutr. Bull. 12: 3.

Shariff, Z.M., Bond, J.T. and Johnson, N.E. (2000). Nutrition and educational achievement of urban primary school children in Malaysia. Asia Pasic J Clin Nutr. 9(4), 264-273

Stoltzfus, R., Albonico. M., Tieslch, J.M., Chwaya, H., Savioli, L., Linear growth retardation in Zanzibar school. J Nutr 1997; 127, 1099-1105.

Themane, M.J., Monyeki, K.D., Nthangeni, M.E., Kemper, H.C.G. and Twisk, J.W.R. (2003). The relationship between health (malnutrition) and educational achievements (Maths and English) in the rural children of South Africa. Int. J. Edu. Develop. 23, 637-643. 
Thilakarathne, R.M.L.R. and Wijesinghe, D.G.N.G. (2011). Association between nutritional status and life style practices of primary school children in the Colombo District: A pilot Study. Tropical Agricultural Research Vol.22(4), 392-401.

UNESCO (1984). Nutrition and educational achievement. Monograph of the UNESCO nutrition education programme. Nutrition Education Series Issue 9. UNESCO, Paris.

Werner, D. (1987). Disabled village children: A guide for community health workers, rehabilitation workers, and families. Hesperian Foundation, Palo Alto, California, USA.

WHO (1995). Physical status: the use and interpretation of anthropometry. Report of a WHO Expert Committee. Technical Report Series No. 854. World Health Organization, Geneva.

Wijesiriwardane, P. and Amaranath,S. (2009). Inadequate schooling in Sri Lanka's plantations

[on line]. [Accessed on 10.03.2012]. Available at

http://www.wsws.org/articles/2009/apr2009/sled-a17.shtml 